Chronic Obstructive Pulmonary Diseases:

Journal of the COPD Foundation

COPD

FOUNDATION

\author{
Editorial
}

\title{
Progress in Alpha-1 Antitrypsin Deficiency: Collaboration as the Foundation of New Knowledge
}

\author{
James K. Stoller, MD, MS ${ }^{1}$
}

Abbreviations: alpha-1 antitrypsin deficiency, AATD; alpha-1 antitrypsin, AAT; chronic obstructive pulmonary disease, COPD; computed tomography, CT; total lung capacity, TLC; functional residual capacity, FRC

Citation: Stoller JK. Editorial. Progress in alpha-1 antitrypsin deficiency: collaboration as the foundation of new knowledge. Chronic Obstr Pulm Dis. 2018;6(1):1-5. doi: https://doi.org/10.15326/jcopdf.6.1.2018.0164

\section{Education Institute, Cleveland Clinic, Cleveland, Ohio}

\section{Address correspondence to:}

James K. Stoller, MD, MS

Cleveland Clinic

9500 Euclid Ave. Cleveland, Ohio 44195

Phone: (216) 444-1960

Email: stollej@ccf.org

\section{Keywords:}

alpha-1 antitrypsin deficiency; chronic obstructive pulmonary disease

\section{Introduction}

As a measure of the importance of alpha- 1 antitrypsin deficiency (AATD), 3 papers in this current issue of Chronic Obstructive Pulmonary Diseases: Journal of the COPD Foundation regard AATD. These papers by Choate et al, ${ }^{1}$ Sieluk et al, ${ }^{2}$ and Brantly et al ${ }^{3}$ highlight advances in understanding this important but highly under-recognized condition. ${ }^{4,5}$ This editorial hopes to frame these diverse papers within current knowledge regarding AATD and to emphasize ways in which these studies reflect a special, collaborative scientific milieu that surrounds AATD. ${ }^{6}$ The papers respectively compare features of individuals with the $\mathrm{PI} Z \mathrm{ZZ}$ versus $\mathrm{PI}^{*} \mathrm{SZ}$ genotype, ${ }^{1}$ present the costs of treating AATD, ${ }^{2}$ and review available data regarding the efficacy of augmentation therapy for AATD - the intravenous infusion of pooled human plasma-derived alpha-1 antitrypsin (AAT). ${ }^{3}$

\section{Background}

By way of background, AATD is a relatively common but under-recognized autosomal co-dominant condition which predisposes to emphysema, panniculitis, and cirrhosis. ${ }^{4,5}$ Of the $>200$ alleles described, the $\mathrm{Z}$ allele is the most common severe deficiency type and $\mathrm{PI}^{*} \mathrm{ZZ}$ homozygotes are at risk for liver and lung disease. Estimates suggest that $~ 100,000$ Americans are $\mathrm{PI}^{*} \mathrm{ZZ}$ but - highlighting the ongoing challenge of detection - fewer than 10,000 have been diagnosed presently. ${ }^{4}$ Worldwide, there are an estimated 181,894 $\mathrm{PI}^{*} \mathrm{ZZ}$ individuals. ${ }^{7}$ Similarly, most are undetected. ${ }^{8}$ As manifestations of this continuing under-recognition, affected individuals with severe deficiency of AAT often experience long diagnostic delays and see multiple health care providers between their initial symptom and first diagnosis. ${ }^{9,10}$ These delays are associated with adverse clinical effects. ${ }^{11}$

First described in 1963 by Laurell and Eriksson in Malmo, Sweden, ${ }^{12}$ AATD has been extensively studied since, with substantial strides made in understanding the detection, pathobiology, molecular biology, and treatment of AATD. Selected milestones in this understanding of AATD include: the first description of AATD in $1963,{ }^{12}$ the first report of liver disease associated with AATD by Sharp et al in $1969,{ }^{13}$ formation of the National Heart Lung and Blood Institute Registry for Individuals with AATD in $1988^{14,15}$ and the Alpha-1 International Registry to characterize the population and the natural history of AATD, ${ }^{16}$ elucidation of the misfolding and 
intrahepatocyte polymerization that characterizes the PI*ZZ state, ${ }^{17}$ initiation of large population-based screening studies in Sweden and the United States, ${ }^{18,19}$ the formation of the Alpha-1 Foundation to broker interactions between the stakeholder communities in $1995,{ }^{6}$ the description of and initial United States Food and Drug Administration approval of augmentation therapy in 1987, and, more recently, investigation of a number of novel potential therapies (including gene therapy, corrector molecules, and interfering mRNA, among others). On the basis of these many strides, in the current era of precision medicine and focus on distinctive endotypes in chronic obstructive pulmonary disease (COPD), AATD can be regarded as the first well-characterized COPD endotype.

\section{Team Science}

Importantly, as demonstrated by the papers in this volume and by the very existence of this journal (which began after the COPD Foundation formed as an expansion of its predecessor, the Alpha-1 Foundation), the strides in understanding AATD over its nearly 56-year history represent the outcomes of exemplary collaborations among various communities, all in service of helping patients and pursuing a cure for AATD. Key participants in this collaboration have been the AATD patient community - so-called "alphas" among whom visionary "impatient patient" leaders like the late John Walsh have demonstrated simply inspirational leadership ${ }^{6}$; patient advocacy and support organizations like the Alpha-1 Foundation which have brokered relationships between the patient community, clinicians, scientists, government, and pharma and funded research ${ }^{6}$; the clinical and scientific communities of physicians who care for alphas and scientists who investigate AATD; governmental funding agencies like the National Heart, Lung, and Blood Institute which have helped shape and fund key studies ${ }^{14,15}$; and the pharmaceutical industry which has sponsored research and scholarship, ${ }^{3}$ manufactures and has driven approval of augmentation therapy for AATD, and is advancing new therapeutic ideas. As evidence of the power of this collaborative milieu around AATD, 2 of the 3 papers in this volume were funded by AlphaNet, ${ }^{1,2}$ a patient support organization that emerged from the Alpha- 1 Foundation ${ }^{6}$ and that provides infusion services and support to the alpha-1 community; AlphaNet provides funding to support the mission of the Alpha-1 Foundation, which is "finding a cure for alpha-1 antitrypsin deficiency and improving the lives of people affected by alpha-1 worldwide." ${ }^{20}$ Through an active grants program and committed volunteers from the scientific, clinical, and patient communities, the Alpha-1 Foundation in turn has issued \$71 million in grants to support AATD research since its inception in $1995 .^{20}$

How then do these 3 papers reflect and contribute to the ever-growing knowledge base about AATD and what are the takeaways from these papers for the clinician? First, the paper by Choate et al ${ }^{1}$ examines self-reported differences between individuals with the PI*ZZ versus PI*SZ genotype. Notwithstanding the risks of bias related to self-reported data from a cohort ascertained by their participating in a disease management program, this paper extends prior reports from smaller cohorts of $\mathrm{PI}^{*} \mathrm{SZ}$ individuals ${ }^{21-23}$ by newly describing lifestyle and quality of life-related features of having $\mathrm{PI}^{*} \mathrm{SZ}$ AATD. As $\mathrm{PI}^{*} \mathrm{SZ}$ individuals differ from $\mathrm{PI}^{*} \mathrm{ZZ}$ individuals in important ways (e.g., $\mathrm{PI}^{*} \mathrm{SZ}$ individuals reported more exacerbations and hospitalizations than their PI*ZZ counterparts), this paper emphasizes the critical importance of genotyping at-risk individuals for AATD, as has been advocated in recent guidelines. ${ }^{24}$ Because having AATD has consequences for the proband and also potentially for his/her family, establishing the diagnosis of AATD and the specific genotype is critical. Furthermore, because clinical features among $\mathrm{PI}^{*} \mathrm{SZ}$ and $\mathrm{PI}^{*} \mathrm{ZZ}$ individuals differ with different interventional opportunities suggested by Choate et al, testing for AATD must include not only a serum level but also a genotype.

Recognizing how impactful the development and registration of augmentation therapy has been for individuals with AATD, the papers by Brantly et $\mathrm{al}^{3}$ and Sieluk et $\mathrm{al}^{2}$ remind us that many questions and challenges persist in understanding the effectiveness of augmentation therapy and whether augmentation therapy can be widely available to all eligible patients. Taken together, the weight of evidence from 3 randomized placebo-controlled trials and many observational studies of augmentation therapy clearly supports the efficacy of augmentation therapy to slow the progression of emphysema due to AATD. At the same time, because of the challenges of studying an uncommon disease, none of the 3 randomized trials of augmentation therapy is individually definitive. 
For example, as Brantly et $\mathrm{al}^{3}$ point out, the primary endpoint in the RAPID trial using computed tomography (CT) density based on both total lung capacity (TLC) and functional residual capacity (FRC) actually failed to achieve statistical significance, ${ }^{3,25}$ though multiple other endpoints in the trial clearly support efficacy, including the significantly lower rate of density loss using TLC-based CT lung density change, and the evident slowing of density decline when individuals initially randomized to placebo crossed over to active drug in the open label extension of the RAPID trial. ${ }^{26}$

In a similar vein, Sieluk et $\mathrm{al}^{2}$ present an analysis of the actual costs associated with having AATD. A key finding is that the estimated total annual cost of treatment for AATD in augmentation therapy users is $\$ 127,537$, of which $75.3 \%$ is ascribed to the cost of augmentation therapy itself. Fortunately, for those with insurance, the vast majority of the expense is born by insurance, with the average annual out-ofpocket expense for augmentation therapy much less at $\$ 2084$. Yet, clinical experience clearly shows that the cost of augmentation therapy remains an impediment to full access to the drug for all eligible patients. As novel therapies emerge, whether gene therapy, corrector molecules, or RNA interference to suppress $Z$ protein production, the affordability of therapy must be a paramount consideration. ${ }^{27-29}$

Taken together, the findings in these 3 papers address a spectrum of issues that surround AATD - how to detect affected individuals, how to treat patients with established emphysema, and the costs of therapy that impact access and affordability of care. These studies, like the journal in which they are published, tangibly exemplify ways in which the pharmaceutical, patient, and clinical/scientific communities have joined to study AATD in service of improving the lives of affected individuals and curing AATD. Having drawn the attention of AATD investigators from multiple disciplines, including pulmonary medicine, adult and pediatric hepatology, pharmacoeconomics, structural biology, and epidemiology, among others, AATD is not only the first well-characterized COPD endotype but also an early and powerful example of "team science." 30 The model invites emulation. 


\section{References}

1. Choate R, Mannino DM, Holm KE, Sandhaus R. Comparing patients with ZZ versus SZ alpha- 1 antitrypsin deficiency: findings from AlphaNet's disease management program. Chronic Obstr Pulm Dis. 2019;6(1):29-39. doi: http://dx.doi.org/10.15326/jcopdf.6.1.2018.0134

2. Sieluk J, Levy J, Sandhaus RA, Silverman H, Holm KE, Mullins $C D$. Costs of medical care among augmentation therapy uses and non-users with alpha-1 antitrypsin deficiency in the United States. Chronic Obstr Pulm Dis. 2019;6(1):6-16. doi: http://dx.doi.org/10.15326/jcopdf.6.1.2017.0187

3. Brantly ML, Lascano JE, Shahmohammadi A. Intravenous alpha-1 antitrypsin therapy for alpha-1 antitrypsin deficiency: the current state of the evidence. Chronic Obstr Pulm Dis. 2019; 6(1):100-114.

doi: http://dx.doi.org/10.15326/jcopdf.6.1.2017.0185

4. Stoller JK, Aboussouan LS. A review of alpha-1 antitrypsin deficiency. Am J Respir Crit Care Med. 2012;185(3):246-259. doi: https://doi.org/10.1164/rccm.201108-1428CI

5. American Thoracic Society, European Respiratory Society. American Thoracic Society/European Respiratory Society statement: Standards for the diagnosis and management of individuals with alpha-1 antitrypsin deficiency. Am J Respir Crit Care Med. 2003;168(7):816-900.

doi: https://doi.org/10.1164/rccm.168.7.818

6. Walsh JW, Snider GL, Stoller JK. A review of the Alpha-1 Foundation: formation, impact, and critical success factors. Respir Care. 2006;51(5):526-531.

7. Blanco I, Lara B, de Serres F. Efficacy of alpha-1 antitrypsin augmentation therapy in conditions other than pulmonary emphysema. Orphanet J Rare Dis. 2011;6:14. doi: https://doi.org/10.1186/1750-1172-6-14

8. Stoller JK, Brantly M. The challenge of detecting alpha-1 antitrypsin deficiency. COPD. 2013; 10(sup1):26-34. doi: https://doi.org/10.3109/15412555.2013.763782

9. Campos MA, Wanner A, Zhang G, Sandhaus RA. Trends in the diagnosis of symptomatic patients with alpha-1 antitrypsin deficiency between 1968 and 2003. Chest. 2005;128(3);11791186. doi: https://doi.org/10.1378/chest.128.3.1179

10. Stoller JK, Sandhaus RA, Turino G, et al. Delay in diagnosis of alpha-1 antitrypsin deficiency: A continuing problem. Chest. 2005;128(4):1989-1994.

doi: https://doi.org/10.1378/chest.128.4.1989

11. Tejwani V, Nowacki A, Fye E, Sanders C, Stoller JK. The impact of delayed diagnosis of alpha-1 antitrypsin deficiency: The association between diagnostic delay and worsened clinical status. Respir Care. In press.
12. Laurell CB, Eriksson S. The electrophoretic alpha-1 globulin pattern of serum in alpha-1 antitrypsin deficiency. Scand J Clin Lab Invest. 1963;15(2):132-140.

doi: https://doi.org/10.1080/00365516309051324

13. Sharp HL, Bridges RA, Krivit W, Freier EF. Cirrhosis associated with alpha-1 antitrypsin deficiency: A previously unrecognized inherited disorder. J Lab Clin Med. 1969;73:934-939.

14. National Heart Lung and Blood Institute. Survival and FEV1 decline in individuals with severe deficiency of alpha-1 antitrypsin deficiency. The alpha-1 antitrypsin deficiency registry study group. Am J Respir Crit Care Med. 1998;158(1):4959. doi: https://doi.org/10.1164/ajrccm.158.1.9712017

15. McElvaney NG, Stoller JK, Buist AS, et al. Baseline characteristics of enrollees in the National Heart, Lung and Blood Institute Registry of Alpha-1 antitrypsin Deficiency. Alpha-1 antitrypsin Deficiency Registry Study Group. Chest. 1997;111(2):394-403. doi: https://doi.org/10.1378/chest.111.2.394

16. Stockley RA, Luisetti M, Miravitlles M, et al. Ongoing research in Europe: Alpha One International Registry (AIR) objectives and development. Eur Resp J. 2007;29(3):582-586. doi: https://doi.org/10.1183/09031936.00053606

17. Carrell RW, Lomas DA. Alpha-1 antitrypsin deficiency: a model for conformational diseases. N Engl J Med. 2002;346:45-53. doi: https://doi.org/10.1056/NEJMra010772

18. Sveger T. Liver disease in alpha- 1 antitrypsin deficiency detected by screening of 200,000 infants. N Engl J Med. 1976;294:13161321. doi: https://doi.org/10.1056/NEJM197606102942404

19. O’Brien ML, Buist NR, Murphey WH. Neonatal screening for alpha-1 antitrypsin deficiency. J Pediatr. 1978; 92(6):1006-1010. doi: https://doi.org/10.1016/S0022-3476(78)80388-6

20. Alpha-1 Foundation. About us. Alpha-1 Foundation website. https://www.alpha1.org/What-is-the-Alpha-1-Foundation/ About-Us Accessed January 2019.

21. Lara B, Miravitlles M. Spanish registry of patients with alpha-1 antitrypsin deficiency: Comparison of the characteristics of $\mathrm{PI}^{*} \mathrm{SZ}$ and PI*ZZ individuals. COPD. 2015;12(suppl 1):27-31. doi: https://doi.org/10.3109/15412555.2015.1021912

22. Turino GM, Barker AF, Brantly ML, et al. Alpha-1 Antitrypsin Deficiency Registry Study Group. Clinical features of individuals with PI*SZ phenotype of alpha-1 antitrypsin deficiency. Am J Respir Crit Care Med. 1996;154(6):1718-1725. doi: https://doi.org/10.1164/ajrccm.154.6.8970361

23. Holme J, Stockley R. CT scan appearance, densitometry, and health status in protease inhibitor SZ alpha-1 antitrypsin deficiency. Chest. 2009;136:1284-1290. doi: https://doi.org/10.1378/chest.09-0057 
24. Sandhaus RA, Turino G, Brantly ML, et al. The diagnosis and management of alpha-1 antitrypsin deficiency in the adult. Chronic Obstr Pulm Di. 2016;3(3):668-682. doi: http://dx.doi.org/10.15326/jcopdf.3.3.2015.0182

25. Chapman KR, Burdon JG, Piitulainen E, et al. Intravenous augmentation treatment and lung density in severe a1 antitrypsin deficiency (RAPID): a randomised, double-blind, placebo-controlled trial. Lancet. 2015;386(9991):360-368. doi: https://doi.org/10.1016/S0140-6736(15)60860-1

26. McElvaney NG, Burdon J, Holmes M, et al. Long-term efficacy and safety of a1 proteinase inhibitor treatment for emphysema caused by severe a1 antitrypsin deficiency: an open-label extension trial (RAPID-OLE). Lancet Respir Med. 2017;5(1):5160. doi: https://doi.org/10.1016/S2213-2600(16)30430-1

27. Mullins CD, Huang X, Merchant S, Stoller JK. Alpha One Foundation Research Network Registry Investigators. The direct medical costs of alpha-1 antitrypsin deficiency. Chest. 2001; 119(3):745-752. doi: https://doi.org/10.1378/chest.119.3.745

28. Gildea TR, Shermock KM, Singer ME, Stoller JK. Costeffectiveness and analysis of augmentation therapy for severe alpha-1 antitrypsin deficiency. Am J Respir Crit Care Med. 2003;167(10):1387-1392.

doi: https://doi.org/10.1164/rccm.200209-1035OC

29. Hay JW, Robin ED. Cost-effectiveness of alpha-1 antitrypsin replacement therapy in treatment of congenital chronic obstructive pulmonary disease. Am J Pub Health. 1991; 81(4):427-433. doi: https://doi.org/10.2105/AJPH.81.4.427

30. Stokols D, Hall KL, Taylor BK, Moser RP. The science of team science: Overview of the field and introduction to the supplement. Am J Prev Med. 2008;35:S77-S89. doi: https://doi.org/10.1016/j.amepre.2008.05.002 